\title{
Bruno Roche, Le Rire des libertins dans la première moitié du XVII siècle
}

\section{Laura Rescia}

\section{OpenEdition}

\section{Journals}

\section{Edizione digitale}

URL: https://journals.openedition.org/studifrancesi/4659

DOI: 10.4000/studifrancesi.4659

ISSN: 2421-5856

\section{Editore}

Rosenberg \& Sellier

\section{Edizione cartacea}

Data di pubblicazione: 1 avril 2012

Paginazione: $139-140$

ISSN: 0039-2944

\section{Notizia bibliografica digitale}

Laura Rescia, "Bruno Roche, Le Rire des libertins dans la première moitié du xvI" siècle», Studi Francesi [Online], 166 (I | LVI) | 2012, online dal 30 novembre 2015, consultato il 19 novembre 2021. URL: http:// journals.openedition.org/studifrancesi/4659 ; DOI: https://doi.org/10.4000/studifrancesi.4659

Questo documento è stato generato automaticamente il 19 novembre 2021.

\section{@(๑) $\Theta \Theta$}

Studi Francesi è distribuita con Licenza Creative Commons Attribuzione - Non commerciale - Non opere derivate 4.0 Internazionale. 


\title{
Bruno Roche, Le Rire des libertins dans la première moitié du XVII siècle
}

\author{
Laura Rescia
}

\section{NOTIZIA}

BRUNO ROCHE, Le Rire des libertins dans la première moitié du XVII siècle, Paris, Honoré Champion, 2011, «Libre pensée et Littérature clandestine», pp. 624.

1 Bruno Roche affronta una problematica che si presenta doppiamente insidiosa per l'intrinseca vischiosità dei due fenomeni che si propone di mettere in rapporto. Notoriamente, l'ironia e il ridicolo veicolano una visione del mondo che, pur connotando buona parte della produzione letteraria libertina della prima metà del secolo, non può essere considerata prerogativa esclusiva del pensiero libertino, a sua volta estremamente scivoloso e di difficile delimitazione. L'introduzione al volume, che raccoglie i risultati di una tesi di dottorato diretta da Dominique Bertrand, affronta dunque in primis le difficoltà metodologiche di tale impresa, ponendosi in immediata contiguità con le ultime tendenze critiche sul libertinaggio. Seguendo J. C. Cavaillé, Roche afferma la non separabilità di libertinage de mours e libertinage érudit; si schiera inoltre a favore di coloro che considerano l'ateismo elemento fondativo del fenomeno libertino; e rivolge infine la sua attenzione agli strumenti d'indagine del discorso, usandoli come grimaldello per indagare la ben nota ambiguità dei testi libertini. Il suo eterogeneo corpus prende l'avvio dagli anni Venti del secolo e si estende fino al 1655, con l'eccezione di Charles Dassoucy, la cui opera viene inclusa benché oltrepassi il limite cronologico prefissato. Il corpus preso in esame mette utilmente in prospettiva opere filosofiche e letterarie, nell'intento di superare una dicotomia che Pintard riteneva invece ineludibile.

2 Ne risulta un corposo lavoro, suddiviso in quattro parti. La prima è utile a definire l'atteggiamento del libertino nel campo sociale. Il riso rivela la posizione di superiorità che può diventare un'indicazione di metodo: così Théophile de Viau, per contrastare 
l'imperante persuasione dell'immagine operata dalla Controriforma, sembrerebbe additare la necessità di un procedimento analitico basato sull'osservazione diretta dei fenomeni e l'applicazione del principio dialogico, utile a demistificare tanto il rito religioso come il sentimento amoroso. Analoga presa di distanza si ritrova tanto negli scritti di Tristan l'Hermite che in quelli di Gabriel Naudé. La seconda e la terza parte si articolano rispettivamente intorno alle strategie di creazione di significato e di denegazione dello stesso che la risata libertina comporta. La derisione dei dogmi cattolici si opererebbe attraverso la condanna dell'eccesso del petrarchismo, delle insufficienze dell'aristotelismo scolastico e la critica all'eccessivo ampliamento del concetto di Provvidenza. Le strategie di dissimulazione, e il gioco ironico in particolare, si articolerebbero attraverso una triplice operazione di sdoppiamento: dell'emittente, tramite l'uso di una calcolata ipocrisia; del messaggio, utilizzando tutto l'apparato retorico classico - antitesi, aposiopesi, incompletezza dei sillogismi, uso di argomenti deboli; e del pubblico, utilizzando un 'montaggio scenografico' che presuppone la possibilità di un doppio livello di ricezione, del censore e del lettore complice. In questa interessante rassegna l'A. dimostra come tipologie testuali molto diverse, quali quelle praticate da Sorel e da La Mothe le Vayer, utilizzino identiche strategie discorsive a vantaggio del messaggio caché.

3 La quarta e ultima parte si concentra sull'analisi del trattamento delle passioni del libertino: attraverso la riabilitazione del riso si apre la possibilità di rivalutare le passioni, che il riso contribuisce a regolare, fondando una nuova antropologia positiva, all'insegna della triade jouir-savoir-pouvoir. Anche l'utopia sarebbe leggibile attraverso la chiave ironica e distanziatoria del discorso libertino.

4 Ispirato alle più recenti e innovative prospettive critiche, questo lavoro, intellettualmente vivace ed assai esteso, trova un limite in una presentazione dei risultati talvolta artificiosa, fors'anche derivata da un approccio metodologico eterogeneo, rivendicato dall'autore come unico possibile per un corpus di tale natura. Rimane di estremo interesse l'ambizione, in diversi tratti pienamente riuscita, di abbinare testi filosofici e letterari, spaziando in un universo che della diversità fa la propria devise. 